\title{
ANÁLISE DE CLIMA ORGANIZACIONAL EM EMPRESAS ATUANTES NO SETOR DE SERVIÇOS DO SERTÃO CENTRAL: UMA ANÁLISE MULTICASO NA CIDADE DE SALGUEIRO-PE
}

\author{
Emanuela de Fátima Carvalho (UNIVERSIDADE DE PERNAMBUCO) emanuela-carvalho@outlook.com \\ Éverton Crístian Rodrigues de Souza (UNIVASF) everton.souza@univasf.edu.br \\ Rafaela Torres Dos Santos (UNIVERSIDADE DE PERNAMBUCO) adm.rafaelatorres@gmail.com \\ Lívia Jordana Gois e Silva Patriota (UNIVERSIDADE DE PERNAMBUCO) liviajordanap@gmail.com \\ Maria Fernanda Angelo do Carmo (UNIVASF) angelllmafe@ gmail.com
}

\begin{abstract}
Resumo
O setor de serviços nos últimos tempos tem crescido de forma considerável e ampliado sua importância no contexto econômico nacional. No entanto, foi classificado como um setor de baixa produtividade (IPEA, 2015). Considerando o argumento de Luz (2001), em que o clima organizacional constitui um elemento capaz de influenciar na satisfação, motivação e produtividade dos colaboradores de uma empresa, essa pesquisa teve como objetivo analisar o clima organizacional de três empresas atuantes no setor de serviços do sertão central. De cunho descritivo e abordagem qualitativa, três organizações constituíram o ambiente de pesquisa, duas empresas que prestam serviços de contabilidade e uma agência bancária. $\mathrm{O}$ método escolhido para a obtenção de dados foi o levantamento, realizado pela aplicação de um questionário desenvolvido por Bispo (2006), o qual pode ser considerado um modelo inovador de pesquisa de clima organizacional, aplicável em empresas de qualquer ramo de atuação, tanto públicas quanto privadas. Verificou-se a satisfação dos colaboradores a respeito de aspectos internos e externos ao ambiente organizacional e identificados os elementos causadores de insatisfação entre os indivíduos incluídos na amostra. Foram poucos os aspectos internos e externos ao ambiente organizacional causadores de insatisfação entre os colaboradores das empresas analisadas. O único elemento interno que se apresentou como promotor de insatisfação entre os colaboradores foi o aspecto assistência aos funcionários. Quanto aos elementos externos indicaram: time de futebol, política e economia e segurança pública.
\end{abstract}

Palavras-Chaves: (Clima Organizacional. Serviços. Produtividade)

\section{Introdução}

O setor de serviços tem se expandido cada vez mais e ampliado sua importância na economia do país. Corresponde atualmente a mais de $70 \%$ do Produto Interno Bruto brasileiro (PIB), entretanto é caracterizado como um setor de baixa produtividade, onde são empregues para sua realização imensas quantidades de recursos a custos relativamente altos (TORRES, LOPES, 2013, p. 319). Trata-se, então, de uma problemática relativa à produtividade do setor.

Robbins (2005) destaca que uma empresa é produtiva quando atinge seus objetivos e converte a matéria bruta da qual dispõe em produtos ou serviços a um custo relativamente baixo. 
Assim, as organizações que se preocupam com a correta gestão de seus recursos colocam-se à frente da concorrência, pois, aumentando a produtividade, os custos relativos à produção e/ou aos serviços prestados são reduzidos, na medida em que começam a ser produzidos de forma mais eficiente e sem desperdícios, podendo ser apresentados ao mercado a um preço acessível (MOREIRA, 2008).

Urdan e Urdan (2013) apontam em seus estudos que uma das principais características do referido setor é ser intensivo em mão de obra, sendo o homem para, Marras (2002), o elemento principal do processo produtivo. Este, de acordo com a teoria da motivação desenvolvida por Herzberg e apresentada por Robbins (2000) pode ter sua satisfação e motivação influenciada por inúmeros elementos, que podem ser tanto intrínsecos, quanto extrínsecos ao ambiente organizacional.

Bispo (2006) elencou alguns influenciadores do comportamento dos colaboradores que impactam diretamente no clima organizacional, quais sejam: incentivos profissionais, remuneração, segurança profissional, nível sociocultural, ambiente de trabalho, cultura organizacional, assistência aos funcionários, férias e lazer, segurança pública e política e economia.

O Clima Organizacional (CO), na visão de Maximiano (2010), é o conjunto de sentimentos comuns partilhados por colaboradores em um momento específico a respeito do ambiente de trabalho em que atuam. O CO não é constante, uma vez que advém da relação entre sujeitos subjetivos, que percebem os fatos e reagem a estes, de maneiras diversas.

Luz (2001) enfatiza que, por meio da análise de clima organizacional, se consegue perceber a satisfação material e emocional dos colaboradores acerca dos fatores relativos ao seu ambiente de trabalho, como também aspectos externos a este. A importância da verificação dele encontra-se no fato de que o CO tem o poder de influenciar na produtividade, satisfação e motivação dos colaboradores de uma empresa.

Assim, este trabalho teve como principal objetivo analisar o clima organizacional de três empresas atuantes no setor de serviços do sertão central. Para Bispo (2006), entre as inúmeras ferramentas desenvolvidas atualmente para avaliar a relação entre organizações e colaboradores, a pesquisa de clima organizacional constitui um método extremamente eficaz, capaz de detectar com êxito problemas relativos à gestão dos recursos humanos.

Na visão de Wada (2002), a existência de uma relação satisfatória entre empresas e colaboradores é de extrema importância, uma vez que desestruturada pode ocasionar 
múltiplas perdas para ambas as partes, haja vista que somente colaboradores satisfeitos são capazes de realizar clientes. A satisfação gera motivação e essa se apresenta como um elemento capaz de interferir no desempenho dos indivíduos. Dessa forma, a pesquisa construiu-se com base na seguinte problemática: Como se encontra o clima organizacional das empresas atuantes no setor de serviços?

\section{Referencial teórico}

\subsection{O clima organizacional e a produtividade}

As organizações são constituídas pela união de elementos diversos. Suas interações produzem características específicas e peculiares, como a cultura organizacional e o clima organizacional. A cultura organizacional é formada pelas ações dos colaboradores ao longo do tempo dentro das organizações, que se consolidam em forma de hábitos e rotina, tornando-se algo difícil a ser modificado, sendo preciso para tal, medidas de médio e longo prazo (TEIXEIRA, 2005).

Em contrapartida, o clima organizacional, na visão de Maximiano (2010), trata-se da junção dos sentimentos e percepções comuns dos colaboradores em um dado momento, a respeito das organizações onde atuam. Esse é inconstante, uma vez que é constituído a partir da relação entre sujeitos subjetivos, com personalidades distintas, que reagem de forma diferente aos fatos e acontecimentos.

A cultura organizacional, de acordo com Luz (2003), da mesma forma que os fatores externos, como aspectos relativos à saúde, moradia e lazer, mostra-se como um elemento capaz de gerar influências positivas e negativas para o CO. Ainda conforme o autor (op. Cit., 2007), o CO é considerado bom se as atitudes positivas forem predominantes, e prejudicado ou ruim quando elementos organizacionais provocam alterações no ânimo dos colaboradores. Bispo (2006) aponta que entre as inúmeras ferramentas desenvolvidas atualmente para avaliar a relação entre organizações e colaboradores, a pesquisa de clima organizacional constitui um método extremamente eficaz, capaz de detectar com êxito problemas relativos à gestão dos recursos humanos.

Bispo (2006) elencou em seu trabalho, fatores internos e externos às organizações de influência para o clima organizacional, são eles: vida profissional, estrutura organizacional, incentivos profissionais, remuneração, segurança profissional, nível sociocultural, transporte dos funcionários, ambiente de trabalho, burocracia, cultura organizacional, assistência aos 
funcionários, investimentos e despesas familiares, convivência familiar, situação financeira, vida social, saúde, time de futebol, férias e lazer, segurança pública e política e economia. Os fatores de influência para o CO são aqueles que interferem na satisfação e, consequentemente, no comportamento dos colaboradores, direta ou indiretamente.

A satisfação é uma conclusão gerada pelo colaborador advinda da percepção que o mesmo tem entre aquilo que deseja e o que na realidade recebe (MARTINEZ, 2002). Já a motivação é algo que nasce no interior de cada pessoa, é um impulso que induz a um tipo de comportamento e tem origem nas necessidades (MAXIMIANO, 2010).

A motivação, de acordo com Gonçalves (2003), é algo que tem forte dependência com outras variáveis, como elementos psicológicos, elementos ligados a aspectos fisiológicos, afetivos ou intelectuais. Bergamini (2008) declara em seus trabalhos que a motivação e a produtividade estão intimamente relacionadas, uma vez que colaboradores motivados apresentam um melhor desempenho e assim, auxiliam as organizações, fazendo com que as mesmas alcancem suas metas.

As organizações precisam constantemente buscar formas para alinhar suas metas aos objetivos pessoais dos colaboradores, de modo que gerem benesses para os dois lados. A análise da satisfação e motivação do quadro de pessoal serve como um termômetro para que as mesmas consigam perceber a eficácia das suas políticas internas, que visem o equilíbrio entre os desejos da organização e os desejos dos colaboradores (PIRES, 2014).

\subsection{O fator humano nas organizações}

Marras (2002) expressa que o ser humano é o elemento mais importante dentro do processo produtivo. Sá (2009) explica que os humanos quando produzem, constroem também a si mesmos, pois o trabalho constitui uma forma utilizada pelo homem para apresentar seu valor como pessoa. Portanto, retirar do colaborador os desafios, as possibilidades dele apresentar seu valor, é retirar também aspectos fundamentais e indispensáveis ao desenvolvimento humano.

O sentimento de valorização otimiza o desempenho, e assim, fatores como absenteísmo e baixa qualidade, tornam-se menos comuns (SANTANA, 2011).

Wagner III (2002) explana que o estado emocional das pessoas é mutável e necessita de gerenciamento, uma vez que negligenciado, ocasiona impactos no desempenho das empresas. 
A liderança dentro das organizações apresenta-se como um fator de extrema importância, pois, de acordo Goleman (2002), liderar é influenciar e persuadir as pessoas em prol da realização de objetivos comuns. O líder é aquele que instiga e transmite confiança aos demais. Nas organizações onde os líderes são confiáveis, observa-se uma maior dedicação por parte da equipe de trabalho (CHESTER ELTON; ADRIAN GOSTICK, 2009).

A confiança é o alicerce de relacionamentos bem estruturados, em que predominam os bons sentimentos. Um ambiente de trabalho onde há confiança torna-se um local adequado para o desenvolvimento de maiores índices de produtividade, uma vez que os medos e a insegurança dos colaboradores são afastados, abrindo espaço para que estes possam desenvolver suas potencialidades (O’ DONNELL, 2006).

Feitas essas considerações acerca do fator humanos nas organizações, é relevante considerar peculiaridades inerentes ao setor de serviço, visto que este é mais dependente da eficácia do front line, e, consequentemente, mais sujeito aos fatores humanos para o bom desempenho. Ademais, esse setor constitui o contexto prático do objeto de pesquisa do presente trabalho. Desse modo, a seção subsequente é dedicada à discussão de características do setor de serviços.

\subsection{O setor de serviços}

"Serviços são os resultados de uma atividade ou série de atividades que, normalmente, envolvem interações entre cliente, funcionários e outros elementos (equipamentos, instalações, procedimentos) do prestador e atendem a necessidades e desejos do cliente" (URDAN; URDAN, 2013, p.204).

A magnitude do setor de serviços apresenta-se de diversas formas. A primeira encontra-se na sua capacidade de gerar riquezas para as nações. E a segunda, em sua acentuada tendência ao crescimento. Uma característica básica do setor de serviços é ser realizado por pessoas, podendo eles serem classificados conforme o grau de contato entre as partes envolvidas (URDAN; URDAN, 2013).

O gerenciamento da qualidade nas organizações prestadoras de serviços é uma forma de se distinguir em meio às demais concorrentes, buscando por meio desta ultrapassar as perspectivas dos seus usuários como forma de fidelizá-los (KOTLER, 2008). “Com tamanha relevância, não é exagero afirmar que o setor de serviços praticamente determina os contornos da economia brasileira" (IPEA, 2015, p. 279), por isso, conhecer todos os dados que possam 
relatar seu desenvolvimento, como também demais indicadores acerca do mesmo, é uma maneira eficiente de identificar os rumos que está tomando e a forma que isso impacta na sociedade com um todo.

\section{Metodologia}

A presente pesquisa caracteriza-se como descritiva, uma vez que tem como objetivo retratar as características de uma população/empresa específica, tal como identificar relações entre variáveis (CERVO; BERVIAN; SILVA, 2007). Quanto à natureza, é qualitativa, "considerando o cunho subjetivo das opiniões dos sujeitos pesquisados" (DESLANDES, 2002, p. 23).

O método escolhido foi o levantamento, que permite ao pesquisador questionar diretamente os indivíduos incluídos no universo que se objetiva conhecer (GIL, 2008). O levantamento dos dados foi realizado por meio da aplicação de um questionário (Anexo A), que consiste em um modelo inovador de pesquisa de clima organizacional desenvolvido por Bispo (2006). O questionário visa analisar a satisfação dos colaboradores com os fatores internos e externos às organizações onde atuam.

Três organizações serviram como ambiente de pesquisa, todas atuantes no setor de serviços, ambiente de intenção e foco nesta pesquisa. A primeira empresa, tratada como empresa A, conta com consideráveis anos de atuação na cidade de Salgueiro e região, e realiza seus trabalhos no ramo da contabilidade. A segunda, também é uma empresa que exerce atividades contábeis, denominada no texto como empresa B. A terceira, foi uma agência bancária, definida como empresa $\mathrm{C}$. Todas tem suas sedes, onde foi realizada a investigação, na cidade de Salgueiro, considerada polo da região do sertão central.

O instrumento aplicado é composto por 61 questões fechadas. Neste existia um espaço aberto onde os colaboradores poderiam deixar suas queixas e sugestões e uma ficha com o objetivo identificar o perfil dos respondentes. Os questionários foram entregues nas empresas em dias diferentes, de acordo com o determinado por cada gestor. O número total de respondentes foi de 70 pessoas. Os fatores incluídos no instrumento, foram estabelecidas por Bispo (2006), e são elucidados nos quadros 1 e 2. 
Quadro 1 - Fatores internos de influência para o clima organizacional

\begin{tabular}{|c|c|}
\hline FATORES & DESCRIÇÃOO \\
\hline $\begin{array}{l}\text { Ambiente de } \\
\text { trabalho }\end{array}$ & $\begin{array}{c}\text { Estabelece o grau de relacionamento entre os colaboradores que é fundamental } \\
\text { para a boa realização das tarefas individuais ou coletivas. }\end{array}$ \\
\hline $\begin{array}{l}\text { Assistência aos } \\
\text { funcionários }\end{array}$ & $\begin{array}{c}\text { Visa estabelecer o nível da assistência médica, dentária, hospitalar e social aos } \\
\text { colaboradores. }\end{array}$ \\
\hline Burocracia & Avalia se está compatível com as atividades desempenhadas. \\
\hline $\begin{array}{l}\text { Cultura } \\
\text { organizacional }\end{array}$ & $\begin{array}{l}\text { Avalia o nível de interferência devido às tradições, práticas e costumes da } \\
\text { empresa que exercem sobre os colaboradores e suas atividades. }\end{array}$ \\
\hline $\begin{array}{c}\text { Estrutura } \\
\text { organizacional }\end{array}$ & $\begin{array}{l}\text { Mede o nível de relacionamento e de capacitação dos funcionários que fazem } \\
\text { parte da estrutura organizacional e sua interferência no trabalho. }\end{array}$ \\
\hline Nível sociocultural & $\begin{array}{l}\text { Estabelece se os níveis intelectual, cultural e social dos colaboradores estão em } \\
\text { pleno acordo com as necessidades ligadas aos seus trabalhos. }\end{array}$ \\
\hline $\begin{array}{l}\text { Incentivos } \\
\text { profissionais }\end{array}$ & Estabelece o nível de reconhecimento profissional dos colaboradores. \\
\hline Remuneração & Avalia se este item está coerente com as atividades prestadas à organização. \\
\hline $\begin{array}{l}\text { Segurança } \\
\text { profissional }\end{array}$ & Avalia a possibilidade de demissão sem motivo percebido pelos colaboradores. \\
\hline $\begin{array}{l}\text { Transporte } \\
\text { casa/trabalho }\end{array}$ & $\begin{array}{l}\text { Objetiva mensurar o nível de dificuldade que os colaboradores encontram para a } \\
\text { sua locomoção de casa à empresa e vice-versa. }\end{array}$ \\
\hline Vida profissional & $\begin{array}{c}\text { Estabelece o grau de identificação profissional dos colaboradores com a } \\
\text { instituição, bem como o orgulho pelo seu sucesso profissional em relação à } \\
\text { organização. }\end{array}$ \\
\hline
\end{tabular}

Fonte: Bispo (2006).

Quadro 2 - Fatores externos de influência para o clima organizacional 


\begin{tabular}{|c|c|}
\hline FATORES & DESCRIÇÃO \\
\hline Convivência familiar & $\begin{array}{c}\text { Avalia o nível de convivência dos colaboradores com as suas famílias. Este item } \\
\text { é indispensável para uma boa produtividade nas atividades desempenhadas na } \\
\text { organização. }\end{array}$ \\
\hline Férias e lazer & $\begin{array}{l}\text { Avalia o grau de satisfação dos colaboradores com estes itens. Esse fator é } \\
\text { fundamental para garantir uma boa produtividade na empresa. }\end{array}$ \\
\hline $\begin{array}{l}\text { Investimentos e } \\
\text { despesas familiares }\end{array}$ & $\begin{array}{c}\text { Avalia o nível do bem-estar que os colaboradores proporcionam às suas } \\
\text { familias. }\end{array}$ \\
\hline Política e economia & $\begin{array}{c}\text { Avalia o nível de interferência que a política e a economia exercem na } \\
\text { motivação dos colaboradores. }\end{array}$ \\
\hline Saúde & Avalia a opinião dos servidores a respeito de suas saúdes física e mental. \\
\hline Segurança pública & $\begin{array}{l}\text { Avalia o nível de influência da segurança pública na vida cotidiana dos } \\
\text { colaboradores. }\end{array}$ \\
\hline Situação financeira & $\begin{array}{l}\text { Avalia como está a vida financeira dos colaboradores, já que uma boa } \\
\text { remuneração pode não ser suficiente para uma boa situação financeira. }\end{array}$ \\
\hline Time de futebol & $\begin{array}{l}\text { Mede o nível de interferência consequente dos times de futebol exercido sobre a } \\
\text { motivação e a produtividade dos colaboradores. }\end{array}$ \\
\hline Vida social & Avalia o nível de satisfação dos colaboradores com a sua vida social. \\
\hline
\end{tabular}

Fonte: Bispo (2006).

Coletadas as informações necessárias, os dados foram tabulados em planilhas no Microsoft Excel. Logo após, gráficos percentuais foram gerados com base nas planilhas, representando a porcentagem de colaboradores que haviam escolhido cada item disponível como alternativa de resposta nos questionamentos. A partir da análise dos dados, se desenvolveram as conclusões a respeito do clima organizacional das empresas pesquisadas. A seção subsequente relata os resultados alcançados.

\section{Análise e discussão dos resultados}

No que toca ao perfil dos respondentes, contatou-se que na empresa A, $96 \%$ dos colaboradores eram do sexo feminino e $4 \%$ do sexo masculino, na empresa B, $71 \%$ eram do sexo feminino e $29 \%$ do sexo masculino, e na empresa C $50 \%$ eram do sexo feminino e $50 \%$ do sexo masculino. 64\% dos colaboradores da empresa A indicaram ser casados, $27 \%$ solteiros, $4 \%$ viúvos e $5 \%$ divorciados. $57 \%$ dos membros da empresa B se declararam como solteiros e $43 \%$ casados. Na empresa C $56 \%$ dos colaboradores apontaram ser solteiros e $44 \%$ casados.

A maior parte dos membros da empresa A indicou ter de 0 a 2 filhos, estar entre 25 e 30 anos ou 31 a 40 anos e ganhar de 2 a 3 salários mínimos. Os da empresa B em sua maioria, não tinham filhos e apresentaram estar entre 25 e 30 anos e ganhar 1 salário mínimo. Já os 
colaboradores da empresa $\mathrm{C}$, indicaram ter de 0 e 2 filhos, estar numa faixa etária entre 25 a 30 ou 36 a 40 anos e ganhar mais de três salários mínimos.

O Quadro 3 é um painel descritivo dos dados coletados nas três empresas. As seções subsequentes os discutem.

\subsection{Fatores internos de influência no CO}

Os membros das três empresas pesquisadas apresentaram satisfação quanto aos seguintes fatores internos considerados por Bispo (2006) como influenciadores do clima organizacional: ambiente de trabalho, burocracia, cultura organizacional, estrutura organizacional, nível sociocultural, incentivos profissionais, remuneração, segurança profissional, transporte casatrabalho e vida profissional. 
Quadro 3 - Painel descritivo dos dados empíricos da pesquisa

\begin{tabular}{|c|c|c|c|c|c|c|c|c|c|c|c|c|c|c|c|}
\hline \multirow[b]{3}{*}{ Abrangência } & \multirow[b]{3}{*}{ Fatores } & \multirow[b]{3}{*}{ Descrição } & \multirow[b]{3}{*}{ Itens do questionário } & \multicolumn{12}{|c|}{ EMPRESA } \\
\hline & & & & & & & & & & & & & & $\mathrm{C}$ & \\
\hline & & & & não & $\begin{array}{c}\text { mais } \\
\text { ou } \\
\text { menos }\end{array}$ & $\operatorname{sim}$ & \begin{tabular}{|c|} 
Não \\
tenho \\
filhos
\end{tabular} & não & $\begin{array}{c}\text { mais } \\
\text { ou } \\
\text { menos }\end{array}$ & $\operatorname{sim}$ & \begin{tabular}{|l} 
Não \\
tenho \\
filhos
\end{tabular} & não & \begin{tabular}{|c} 
mais \\
ou \\
menos
\end{tabular} & Sim & $\begin{array}{l}\text { Não } \\
\text { tenho } \\
\text { filhos }\end{array}$ \\
\hline \multirow{25}{*}{ 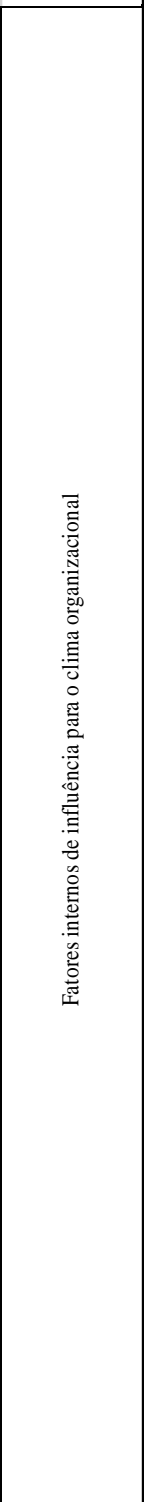 } & \multirow{2}{*}{ Ambiente de trabalho } & \multirow{2}{*}{$\begin{array}{l}\text { Estabelece o grau de relacionamento entre os colaboradores que } \\
\text { é fundamental para a boa realização das tarefas individuais ou } \\
\text { coletivas. }\end{array}$} & $\begin{array}{l}\text { O ambiente de trabalho favorece a execução das minhas atividades } \\
\text { na instituição }\end{array}$ & $0 \%$ & $9 \%$ & $91 \%$ & & $8 \%$ & $15 \%$ & $77 \%$ & & $0 \%$ & $11 \%$ & $89 \%$ & \\
\hline & & & $\begin{array}{l}\text { O relacionamento com meus colegas de trabalho favorece a execução } \\
\text { das minhas atividades na instituição }\end{array}$ & $0 \%$ & $9 \%$ & $91 \%$ & & $8 \%$ & $31 \%$ & $61 \%$ & & $0 \%$ & $0 \%$ & $100 \%$ & \\
\hline & $\begin{array}{c}\text { Assistência aos } \\
\text { funcionários }\end{array}$ & $\begin{array}{l}\text { Visa estabelecer o nível da assistência médica, dentária, } \\
\text { hospitalar e social aos colaboradores. }\end{array}$ & $\begin{array}{l}\text { A assistência de médico e dentista e a assistência social adotadas na } \\
\text { instituição favorecem a execução das minhas atividades na } \\
\text { instituição }\end{array}$ & $100 \%$ & $0 \%$ & $0 \%$ & & $100 \%$ & $0 \%$ & $0 \%$ & & $0 \%$ & $11 \%$ & $89 \%$ & \\
\hline & Burocracia & Avalia se está compatível com as atividades desempenhadas. & $\begin{array}{l}\text { A burocracia adotada na instituição favorece a execução das minhas } \\
\text { atividades }\end{array}$ & $4 \%$ & $22 \%$ & $74 \%$ & & $8 \%$ & $31 \%$ & $61 \%$ & & $0 \%$ & $11 \%$ & $89 \%$ & \\
\hline & Cultura organizacional & $\begin{array}{l}\text { Avalia o nível de interferência devido às tradições, práticas e } \\
\text { costumes da empresa que exercem sobre os colaboradores e suas } \\
\text { atividades. }\end{array}$ & $\begin{array}{l}\text { A Cultura Organizacional (tradições, práticas e costumes adotados } \\
\text { na instituição que não estão previstos em qualquer regra) adotada } \\
\text { na instituição favorece a execução das minhas atividades na } \\
\text { instituição }\end{array}$ & $0 \%$ & $22 \%$ & $78 \%$ & & $15 \%$ & $54 \%$ & $31 \%$ & & $0 \%$ & $33 \%$ & $67 \%$ & \\
\hline & \multirow{4}{*}{ Estrutura organizacional } & \multirow{4}{*}{$\begin{array}{l}\text { Mede o nível de relacionamento e de capacitação dos } \\
\text { funcionários que fazem parte da estrutura organizacional e sua } \\
\text { interferência no trabalho. }\end{array}$} & Eu confio plenamente no meu chefe imediato & $0 \%$ & $26 \%$ & $74 \%$ & & $17 \%$ & $25 \%$ & $58 \%$ & & $0 \%$ & $11 \%$ & $89 \%$ & \\
\hline & & & O meu chefe imediato é um líder & $4 \%$ & $22 \%$ & $74 \%$ & & $8 \%$ & $46 \%$ & $46 \%$ & & $0 \%$ & $11 \%$ & $89 \%$ & \\
\hline & & & $\begin{array}{l}\text { O meu chefe imediato é a pessoa mais indicada para a função que } \\
\text { ocupa }\end{array}$ & $0 \%$ & $26 \%$ & $74 \%$ & & $8 \%$ & $23 \%$ & $69 \%$ & & $0 \%$ & $11 \%$ & $89 \%$ & \\
\hline & & & $\begin{array}{l}\text { Estou satisfeito com a estrutura hierárquica (chefes e subordinados) } \\
\text { a que estou vinculado }\end{array}$ & $0 \%$ & $26 \%$ & $74 \%$ & & $8 \%$ & $15 \%$ & $77 \%$ & & $0 \%$ & $33 \%$ & $67 \%$ & \\
\hline & \multirow{2}{*}{ Nível sociocultural } & \multirow{2}{*}{$\begin{array}{l}\text { Estabelece se os níveis intelectual, cultural e social dos } \\
\text { colaboradores estão em pleno acordo comas necessidades } \\
\text { ligadas aos seus trabalhos. }\end{array}$} & $\begin{array}{l}\text { O meu nível cultural e intelectual é suficiente para o exercício das } \\
\text { minhas atividades na instituição }\end{array}$ & $0 \%$ & $30 \%$ & $70 \%$ & & $0 \%$ & $15 \%$ & $85 \%$ & & $0 \%$ & $22 \%$ & $78 \%$ & \\
\hline & & & $\begin{array}{l}\text { O meu nível social é suficiente para o exercício das minhas } \\
\text { atividades na instituição }\end{array}$ & $0 \%$ & $17 \%$ & $83 \%$ & & $0 \%$ & $8 \%$ & $92 \%$ & & $0 \%$ & $22 \%$ & $78 \%$ & \\
\hline & \multirow{3}{*}{ Incentivos profissionais } & \multirow{3}{*}{$\begin{array}{l}\text { Estabelece o nível de reconhecimento profissional dos } \\
\text { colaboradores. }\end{array}$} & $\begin{array}{l}\text { Considero que o meu trabalho é reconhecido e valorizado pela } \\
\text { instituição }\end{array}$ & $0 \%$ & $30 \%$ & $70 \%$ & & $31 \%$ & $23 \%$ & $46 \%$ & & $11 \%$ & $33 \%$ & $56 \%$ & \\
\hline & & & $\begin{array}{l}\begin{array}{l}\text { Considero que o meu trabalho é reconhecido e valorizado pela minha } \\
\text { família }\end{array} \\
\end{array}$ & $0 \%$ & $9 \%$ & $91 \%$ & & $8 \%$ & $23 \%$ & $69 \%$ & & $0 \%$ & $11 \%$ & $89 \%$ & \\
\hline & & & $\begin{array}{l}\text { Considero que o meu trabalho é reconhecido e valorizado pelos } \\
\text { meus amigos e parentes }\end{array}$ & $0 \%$ & $83 \%$ & $17 \%$ & & $8 \%$ & $38 \%$ & $54 \%$ & & $0 \%$ & $22 \%$ & $78 \%$ & \\
\hline & \multirow[b]{2}{*}{ Remuneração } & \multirow{2}{*}{$\begin{array}{l}\text { Avalia se este itemestá coerente com as atividades prestadas à } \\
\text { organização. }\end{array}$} & Acho justo o meu salário atual & $0 \%$ & $52 \%$ & $48 \%$ & & $31 \%$ & $23 \%$ & $46 \%$ & & $33 \%$ & $45 \%$ & $22 \%$ & \\
\hline & & & $\begin{array}{l}\begin{array}{l}\text { O meu patrimônio é condizente comos esforços que tenho feito pela } \\
\text { instituição }\end{array} \\
\end{array}$ & $17 \%$ & $39 \%$ & $44 \%$ & & $15 \%$ & $39 \%$ & $46 \%$ & & $0 \%$ & $33 \%$ & $67 \%$ & \\
\hline & Segurança profissional & $\begin{array}{l}\text { Avalia a possibilidade de demissão sem motivo percebido pelos } \\
\text { colaboradores. }\end{array}$ & $\begin{array}{l}\begin{array}{l}\text { Meu emprego é seguro na instituição, ou seja, não corro o risco de } \\
\text { ser demitido sem motivo }\end{array} \\
\end{array}$ & $9 \%$ & $26 \%$ & $65 \%$ & & $46 \%$ & $0 \%$ & $54 \%$ & & $11 \%$ & $33 \%$ & $56 \%$ & \\
\hline & Transporte casa/trabalho & $\begin{array}{l}\text { Objetiva mensurar o nível de dificuldade que os colaboradores } \\
\text { encontram para a sua locomoção de casa à empresa e vice-versa. }\end{array}$ & $\begin{array}{l}\text { Tenho tido problemas como transporte casa - instituição/instituição } \\
\text { - casa }\end{array}$ & $78 \%$ & $13 \%$ & $9 \%$ & & $92 \%$ & $0 \%$ & $8 \%$ & & $100 \%$ & $0 \%$ & $0 \%$ & \\
\hline & \multirow{7}{*}{ Vida profissional } & \multirow{7}{*}{$\begin{array}{l}\text { Estabelece o grau de identificação profissional dos colaboradores } \\
\text { coma instituição, bem como o orgulho pelo seu sucesso } \\
\text { profissional em relação à organização. }\end{array}$} & Sinto orgulho de trabalhar nesta instituição & $0 \%$ & $0 \%$ & $100 \%$ & & $8 \%$ & $15 \%$ & $77 \%$ & & $0 \%$ & $0 \%$ & $100 \%$ & \\
\hline & & & Sinto orgulho da minha atividade nesta instituição & $0 \%$ & $0 \%$ & $100 \%$ & & $15 \%$ & $8 \%$ & $77 \%$ & & $0 \%$ & $11 \%$ & $89 \%$ & \\
\hline & & & Acho que a instituição me oferece um bom plano de carreira & $0 \%$ & $48 \%$ & $52 \%$ & & $23 \%$ & $23 \%$ & $54 \%$ & & $0 \%$ & $11 \%$ & $89 \%$ & \\
\hline & & & $\begin{array}{l}\text { Costumo indicar esta instituição como alternativa de emprego para } \\
\text { meus amigos e parentes }\end{array}$ & $9 \%$ & $4 \%$ & $87 \%$ & & $25 \%$ & $23 \%$ & $54 \%$ & & $0 \%$ & $56 \%$ & $44 \%$ & \\
\hline & & & Eu me preocupo como futuro desta instituição & $0 \%$ & $0 \%$ & $100 \%$ & & $8 \%$ & $8 \%$ & $84 \%$ & & $0 \%$ & $0 \%$ & \begin{tabular}{|l}
$100 \%$ \\
\end{tabular} & \\
\hline & & & $\begin{array}{l}\text { Considero que estou obtendo sucesso na minha carreira e na minha } \\
\text { vida profissional }\end{array}$ & $0 \%$ & $39 \%$ & $61 \%$ & & $15 \%$ & $46 \%$ & $39 \%$ & & $0 \%$ & $44 \%$ & $56 \%$ & \\
\hline & & & $\begin{array}{l}\text { Os cursos e treinamentos que fiz são suficientes para o exercício das } \\
\text { minhas atividades }\end{array}$ & $13 \%$ & $48 \%$ & $39 \%$ & & $38 \%$ & $31 \%$ & $31 \%$ & & $11 \%$ & $33 \%$ & $56 \%$ & \\
\hline
\end{tabular}




\begin{tabular}{|c|c|c|c|c|c|c|c|c|c|c|c|c|c|c|c|}
\hline \multirow{32}{*}{ 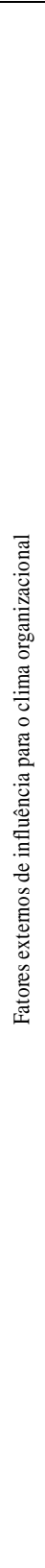 } & \multirow{2}{*}{ Convivência familiar } & \multirow{2}{*}{$\begin{array}{l}\text { Avalia o nível de convivência dos colaboradores com as suas } \\
\text { famílias. Este itemé indispensável para uma boa produtividade } \\
\text { nas atividades desempenhadas na organizaçãa. }\end{array}$} & $\begin{array}{l}\text { Estou vivendo bem com a minha esposa/companheira ou o meu } \\
\text { marido/companheiro }\end{array}$ & $9 \%$ & $13 \%$ & $78 \%$ & & $8 \%$ & $8 \%$ & $84 \%$ & & $22 \%$ & $0 \%$ & $78 \%$ & \\
\hline & & & Estou vivendo bem comos meus filhos & $4 \%$ & $0 \%$ & $57 \%$ & $39 \%$ & $0 \%$ & $0 \%$ & $46 \%$ & $54 \%$ & $0 \%$ & $0 \%$ & $67 \%$ & $33 \%$ \\
\hline & \multirow[b]{2}{*}{ Férias e lazer } & \multirow{2}{*}{$\begin{array}{l}\text { Avalia o grau de satisfação dos colaboradores comestes itens. } \\
\text { Esse fator é fundamental para garantir uma boa produtividade na } \\
\text { empresa. }\end{array}$} & Es tou satisfeito comas minhas últimas férias & $13 \%$ & $22 \%$ & $65 \%$ & & $8 \%$ & $15 \%$ & $77 \%$ & & $11 \%$ & $22 \%$ & $67 \%$ & \\
\hline & & & $\begin{array}{l}\text { Estou planejando para que as minhas próximas férias sejam muito } \\
\text { boas }\end{array}$ & $0 \%$ & $13 \%$ & $87 \%$ & & $0 \%$ & $0 \%$ & $100 \%$ & & $0 \%$ & $11 \%$ & $89 \%$ & \\
\hline & \multirow{4}{*}{$\begin{array}{l}\text { Investimentos e despesas } \\
\text { familiares }\end{array}$} & \multirow{4}{*}{$\begin{array}{l}\text { Avalia o nível do bem-estar que os colaboradores proporcionam } \\
\text { às suas familias. }\end{array}$} & Eu me preocupo como futuro da minha família & $0 \%$ & $0 \%$ & $100 \%$ & & $0 \%$ & $0 \%$ & $100 \%$ & & $0 \%$ & $0 \%$ & $100 \%$ & \\
\hline & & & Eu me preocupo como futuro dos meus filhos & $4 \%$ & $0 \%$ & $57 \%$ & $39 \%$ & $0 \%$ & $0 \%$ & $62 \%$ & $38 \%$ & $0 \%$ & $0 \%$ & $56 \%$ & $44 \%$ \\
\hline & & & $\begin{array}{l}\text { Estou satisfeito com a alimentação que estou podendo proporcionar } \\
\text { à minha família }\end{array}$ & $0 \%$ & $78 \%$ & $22 \%$ & & $8 \%$ & $23 \%$ & $69 \%$ & & $0 \%$ & $11 \%$ & $89 \%$ & \\
\hline & & & $\begin{array}{l}\text { Estou satisfeito com a educação que estou podendo proporcionar } \\
\text { aos mus filhos }\end{array}$ & $13 \%$ & $17 \%$ & $31 \%$ & $39 \%$ & $0 \%$ & $8 \%$ & $46 \%$ & $46 \%$ & $0 \%$ & $11 \%$ & $56 \%$ & $33 \%$ \\
\hline & \multirow{6}{*}{ Política e economia } & \multirow{6}{*}{$\begin{array}{l}\text { Avalia o nível de interferência que a política e a economia } \\
\text { exercem na motivação dos colaboradores. }\end{array}$} & Estou satisfeito como atual estágio da política nacional & $74 \%$ & $13 \%$ & $13 \%$ & & $100 \%$ & $0 \%$ & $0 \%$ & & $67 \%$ & $11 \%$ & $22 \%$ & \\
\hline & & & Estou satisfeito como atual estágio da política estadual & $78 \%$ & $18 \%$ & $4 \%$ & & $77 \%$ & $23 \%$ & $0 \%$ & & $45 \%$ & $44 \%$ & $11 \%$ & \\
\hline & & & Estou satisfeito como atual estágio da política municipal & $78 \%$ & $18 \%$ & $4 \%$ & & $84 \%$ & $8 \%$ & $8 \%$ & & $67 \%$ & $22 \%$ & $11 \%$ & \\
\hline & & & As crises políticas alteram o meu estado de ânimo & $4 \%$ & $31 \%$ & $65 \%$ & & $0 \%$ & $15 \%$ & $85 \%$ & & $0 \%$ & $11 \%$ & $89 \%$ & \\
\hline & & & As crises econômicas alteram o meu estado de ânimo & $4 \%$ & $18 \%$ & $78 \%$ & & $0 \%$ & $0 \%$ & $100 \%$ & & $0 \%$ & $11 \%$ & $89 \%$ & \\
\hline & & & As crises internacionais alteram o meu estado de ânimo & $31 \%$ & $39 \%$ & $30 \%$ & & $23 \%$ & $39 \%$ & $38 \%$ & & $10 \%$ & $40 \%$ & $50 \%$ & \\
\hline & \multirow{3}{*}{ Saúde } & \multirow{3}{*}{$\begin{array}{l}\text { Avalia a opinião dos servidores a respeito de suas saúdes física e } \\
\text { mental. }\end{array}$} & Estou satisfeito com as minhas práticas desportivas & $35 \%$ & $35 \%$ & $30 \%$ & & $31 \%$ & $15 \%$ & $54 \%$ & & $34 \%$ & $33 \%$ & $33 \%$ & \\
\hline & & & Estou satisfeito como meu estado físico & $13 \%$ & $57 \%$ & $30 \%$ & & $23 \%$ & $39 \%$ & $38 \%$ & & $34 \%$ & $33 \%$ & $33 \%$ & \\
\hline & & & Estou satisfeito como meu estado mental & $13 \%$ & $22 \%$ & $65 \%$ & & $23 \%$ & $15 \%$ & $62 \%$ & & $0 \%$ & $44 \%$ & $56 \%$ & \\
\hline & \multirow{4}{*}{ Segurança pública } & \multirow{4}{*}{$\begin{array}{l}\text { Avalia o nível de influência da segurança pública na vida } \\
\text { cotidiana dos colaboradores. }\end{array}$} & Estou satisfeito como atual estágio da segurança pública & $48 \%$ & $35 \%$ & $17 \%$ & & $69 \%$ & $31 \%$ & $0 \%$ & & $56 \%$ & $44 \%$ & $0 \%$ & \\
\hline & & & A corrupção altera o meu estado de ânimo & $4 \%$ & $18 \%$ & $78 \%$ & & $0 \%$ & $15 \%$ & $85 \%$ & & $0 \%$ & $33 \%$ & $67 \%$ & \\
\hline & & & A violência altera o meu estado de ânimo & $0 \%$ & $4 \%$ & $96 \%$ & & $0 \%$ & $15 \%$ & $85 \%$ & & $0 \%$ & $11 \%$ & $89 \%$ & \\
\hline & & & A impunidade altera o meu estado de ânimo & $0 \%$ & $13 \%$ & $87 \%$ & & $8 \%$ & $0 \%$ & $92 \%$ & & $0 \%$ & $0 \%$ & $100 \%$ & \\
\hline & \multirow{5}{*}{ Situação financeira } & \multirow{5}{*}{$\begin{array}{l}\text { Avalia como está a vida financeira dos colaboradores, já que uma } \\
\text { boa remuneração pode não ser suficiente para uma boa situação } \\
\text { financeira. }\end{array}$} & Estou satisfeito com a minha residência & $22 \%$ & $22 \%$ & $56 \%$ & & $8 \%$ & $15 \%$ & $77 \%$ & & $11 \%$ & $22 \%$ & $67 \%$ & \\
\hline & & & Estou satisfeito como meu carro & $52 \%$ & $9 \%$ & $39 \%$ & & $54 \%$ & $15 \%$ & $31 \%$ & & $11 \%$ & $22 \%$ & $67 \%$ & \\
\hline & & & $\begin{array}{l}\text { Estou satisfeito como vestuário que estou podendo proporcionar à } \\
\text { minha familia }\end{array}$ & $13 \%$ & $35 \%$ & $52 \%$ & & $15 \%$ & $31 \%$ & $54 \%$ & & $0 \%$ & $33 \%$ & $67 \%$ & \\
\hline & & & Estou com a minha situação financeira em ordem & $4 \%$ & $61 \%$ & $35 \%$ & & $46 \%$ & $15 \%$ & $39 \%$ & & $11 \%$ & $45 \%$ & $44 \%$ & \\
\hline & & & Estou satisfeito como meu patrimônio & $39 \%$ & $31 \%$ & $30 \%$ & & $46 \%$ & $23 \%$ & $31 \%$ & & $22 \%$ & $33 \%$ & $45 \%$ & \\
\hline & Time de futebol & $\begin{array}{l}\text { Mede o nível de interferência consequente dos times de futebol } \\
\text { exercido sobre a motivação e a produtividade dos colaboradores. }\end{array}$ & Estou satisfeito como time de futebol para o qual eu torço & $57 \%$ & $30 \%$ & $13 \%$ & & $54 \%$ & $8 \%$ & $38 \%$ & & $45 \%$ & $44 \%$ & $11 \%$ & \\
\hline & \multirow{5}{*}{ Vida social } & \multirow{5}{*}{$\begin{array}{l}\text { Avalia o nível de satisfação dos colaboradores com a sua vida } \\
\text { social. }\end{array}$} & Es tou satisfeito como meu nível social & $0 \%$ & $39 \%$ & $61 \%$ & & $8 \%$ & $23 \%$ & $69 \%$ & & $0 \%$ & $22 \%$ & $78 \%$ & \\
\hline & & & Estou satisfeito com o meu convívio social & $0 \%$ & $35 \%$ & $65 \%$ & & $0 \%$ & $15 \%$ & $85 \%$ & & $0 \%$ & $22 \%$ & $78 \%$ & \\
\hline & & & Estou satisfeito como meu nível intelectual & $13 \%$ & $48 \%$ & $39 \%$ & & $8 \%$ & $31 \%$ & $61 \%$ & & $0 \%$ & $11 \%$ & $89 \%$ & \\
\hline & & & Estou satis feito como meu nível cultural & $4 \%$ & $39 \%$ & $57 \%$ & & $23 \%$ & $8 \%$ & $69 \%$ & & $0 \%$ & $0 \%$ & $100 \%$ & \\
\hline & & & Estou satisfeito com a minha religião & $4 \%$ & $9 \%$ & $87 \%$ & & $0 \%$ & $0 \%$ & $100 \%$ & & $0 \%$ & $0 \%$ & $100 \%$ & \\
\hline
\end{tabular}

Fonte: dados da pesquisa (2020) 
O único elemento interno, causador de insatisfação entre os indivíduos das empresas A e B, foi o item assistência aos funcionários. No campo do questionário disponível para queixas e sugestões, este item foi citado por muitos colaboradores como elemento essencial que deveria ser fornecido pelas empresas. Já os colaboradores da empresa C, apresentaram uma realidade contrária à encontrada nas outras duas instituições, apresentando um elevado percentual de satisfação.

As organizações, de acordo com Carvalho e Serafim (2002), devem compreender que os seres humanos são constituídos de necessidades, desejos, entre outras coisas, e para que possam funcionar de maneira eficiente e produtiva, precisam estar bem nos mais variados planos de sua existência. A empresa que disponibiliza assistência aos seus colaboradores, pode, por consequência dispor de equipes mais satisfeitas.

A oferta de incentivos por parte das organizações é um fator que deve sempre ser trabalhado, uma vez que contribui para que essas consigam manter seus colaboradores motivados, estímulos como a oferta de bonificações em dinheiro, cooperam para o desenvolvimento de um ambiente de competitividade (CHIAVENATO, 2008).

Spector (2003) ressalta, que a satisfação das necessidades pelos homens promove uma otimização de sua saúde física e mental. Nesse sentido, seria de relevante interesse para as empresas A e B, que essa variável não se apresentasse como um elemento causador de insatisfação entre os colaboradores.

\subsection{Fatores externos de influência no $\mathrm{CO}$}

No que diz respeito aos elementos externos influenciadores do clima organizacional, foram apontados como fatores promotores de satisfação entre os colaboradores: a convivência familiar, férias e lazer, investimentos e despesas, saúde, situação financeira e vida social.

Quanto aos elementos externos promotores de insatisfação, os seguintes itens foram verificados nas três empresas: política e economia, segurança pública e time de futebol.

A inserção da variável política e economia visava avaliar se esses consistiam em elementos que influenciavam na motivação dos colaboradores. Os indivíduos demonstraram muita insatisfação com o fator política, tanto em relação à política nacional, bem como a política estadual e municipal. Além disso, apontaram que as crises políticas e econômicas alteram seu estado de ânimo. 
Em relação ao item segurança pública, o mesmo permite compreender o quanto esta variável interfere na vida cotidiana dos indivíduos incluídos na amostra. A quase totalidade dos membros participantes, afirmaram que a corrupção, a violência e a impunidade consistem em elementos também capazes de alterar seu estado de ânimo.

O fator time de futebol foi inserido, pois, de acordo com Bispo (2006), constitui um elemento que pode influenciar na motivação e produtividade dos colaboradores. Para Gomes (2003), a motivação causa satisfação e a satisfação causa motivação. Bergamini (2008) declara em seus trabalhos que a motivação e a produtividade estão intimamente relacionadas, uma vez que colaboradores motivados apresentam um melhor desempenho e assim, auxiliam as organizações, fazendo com que elas alcancem suas metas. Logo os resultados empíricos corroboram com a literatura.

No entanto, a insatisfação dos indivíduos com os itens política e economia, segurança pública e time de futebol, constitui algo que não pode ser controlada pelas organizações, uma vez que, a otimização deles depende da atuação de agentes externos específicos. Ainda assim, as consequências são sentidas pelos colaboradores, influenciando o clima organizacional e a produtividade, por conseguinte.

\section{Conclusão}

Diante da necessidade de as empresas ofertarem a seus colaboradores um ambiente onde eles possam crescer e desenvolver suas potencialidades, com políticas que gerem bem estar e realização profissional, a presente pesquisa dedicou-se a investigar o clima organizacional em três organizações prestadoras de serviço.

Nas organizações estudadas, foram poucos os aspectos internos e externos de influência para o clima organizacional, apontados pelos indivíduos como promotores de insatisfação, o que é propício a climas organizacionais positivos, nos quais os indivíduos aparentemente sentem-se bem e dispõem de um ambiente favorável ao desenvolvimento de suas atividades.

As influências verificadas podem direcionar as estratégias adotadas internamente nas organizações, as alternativas de oportunidades, a minimização das ameaças advindas do ambiente externo, e com isto, a correção dos pontos fracos e o fortalecimento dos pontos fortes conforme pontuado na literatura. Para que as empresas consigam otimizar seu clima organizacional, elas precisam passar a compreender cada colaborador como o primeiro cliente 
da organização, uma vez que, cada indivíduo traz em si necessidades a serem supridas (BIEGELMEYER, 2015; WAGNER III, 2002).

Apesar de alguns dos fatores influentes do $\mathrm{CO}$ nas organizações estudadas serem oriundos do ambiente externo, ficou evidenciado que as organizações se importam com seus colaboradores, construindo com esses uma relação de intimidade e confiança, promovem uma maior satisfação. Esse achado motiva futuras investigações com maior amostra de pesquisa e diversidade de setores, para que inferências robustas sobre o cenário empresarial da região possa ser melhor entendido e ações de melhorias gerenciais implementadas.

\section{REFERÊNCIAS}

BERGAMINI, Cecília Whitaker. Motivação nas Organizações: $5^{\mathrm{a}}$ ed. São Paulo: Editora Atlas, 2008.

BISPO, Carlos Alberto Ferreira. Um novo modelo de pesquisa de clima organizacional.

Prod. [online]. 2006, vol.16, n.2, pp.258-273.

BIEGELMEYER, Uiliam; DALBERTO, Mikael; CRACO, Tânia; CAMARGO, Maria Emília; CRUZ, Márcia Rohr da; BERNARDI, Flávia Camargo; FERNANDES, Alice Muniz. Fatores Internos e Externos Influenciam o Clima Organizacional. Revista Espacios, 2015.

CARVALHO, Antônio Vieira de; SERAFIM, Oziléia Clen Gomes. Administração de recursos humanos. Vol. II. São Paulo: Ed. Pioneira, 2002.

CERVO, Amado Luiz; BERVIAN, Pedro Alcino; SILVA, Roberto da. Metodologia Cientifica - $6^{\mathrm{a}}$ Ed. 2007. Pearson Education - Br, 2007.

CHIAVENATO, Idalberto. Administração: teoria, processo e prática. 4. Ed. Rio de Janeiro: Elsevier, 2008.

DESLANDES, Suely Ferreira. Pesquisa Social: teoria, método e criatividade. Petrópolis, RJ: Vozes, 2002.

ELTON, Chester; GOSTICK, Adrian. O Princípio do Reconhecimento. Rio de Janeiro: Elsevier, 2009.

GIL, Antonio Carlos. Métodos e técnicas de pesquisa social. 6.ed. São Paulo: Atlas, 2008

GOLEMAN, Daniel; BOYATZIS, Richard; MCKEE, Annie. O poder da inteligência emocional: a experiência de liderar com sensibilidade e eficácia. Rio de Janeiro: Campus, 2002.

GOMES, Duarte. Cultura organizacional: comunicação e identidade. Coimbra: Quarteto Editora, 2003.

GONÇALVES, Paulo José. Apostila Síntese Motivação. Rio de Janeiro. (2003).

IPEA. Produtividade no Brasil: desempenho e determinantes. 2015.

KOTLER, Philip. Administração de marketing, 2008.

LUZ, Janine Pacheco da. Metodologia para análise de clima organizacional: um estudo de caso para o Banco do Estado de Santa Catarina. Tese (Mestrado) - Programa de Pós-Graduação em Engenharia de Produção da Universidade Federal de Santa Catarina. Florianópolis, 2001.

LUZ, Ricardo Silveira. Gestão do clima organizacional: proposta de critérios para metodologia de diagnóstico, mensuração e melhoria. Estudo de caso em organizações nacionais e multinacionais 
localizadas na cidade do Rio de Janeiro. Tese (Mestrado) - Curso de Mestrado em Sistemas de Gestão da Universidade Federal Fluminense. Niterói, 2003.

MARRAS, Jean Pierre. Administração da Remuneração. São Paulo: Pioneira Thomson Learning, 2002.

MARTINEZ, Maria Carmen. As relações entre a satisfação com aspectos psicossociais no trabalho e a saúde do trabalho. Dissertação de mestrado apresentada ao departamento de saúde pública da Universidade de São Paulo. 2002.

MAXIMIANO, Antonio Cesar Amaru. Introdução à Administração. 7a . ed. São Paulo: Atlas, 2010.

MOREIRA, Daniel Augusto. Administração da produção e operações. $2^{\text {a }}$ edição, 2008.

O’ DONNELL, Ken. Valores Humanos no Trabalho. São Paulo: Gente, 2006.

PIRES, Nilton. A motivação e satisfação organizacional como fatores essenciais de conquista de melhores resultados empresariais: estudo de caso no Hotel Marine Club Beach Resort. Boa Vista: Universidade do Mindelo, 2014.

ROBBINS, Stephen Paul. Administração: mudanças e perspectivas. São Paulo: Saraiva, 2000.

ROBBINS, Stephen Paul. Comportamento organizacional. 11.ed. São Paulo: Prentice Hall, 2002.

SÁ, Kátia de. Motivação dos contadores em seu ambiente de trabalho: Aplicação da teoria dos dois fatores de Frederick Herzberg. TCC (Graduação) - Universidade Federal de Santa Catarina. Centro Socioeconômico. Curso de Ciências Contábeis. 2009.

SANTANA, Talyhane Pires. Motivação no serviço público municipal: um estudo de caso feito à luz da Teoria de Frederick Herzberg. Dissertação da Universidade Federal da Bahia. Salvador/2011.

SPECTOR, Paul E. Psicologia nas organizações. São Paulo: Saraiva, 2003.

TEIXEIRA, Gilnei Mourão. Gestão Estratégica de pessoas. Rio de Janeiro: FGV, 2005.

TORRES, Noel Júnior; LOPES; Ana Lúcia Miranda Lopes. produtividade em serviços: uma análise à luz da revisão sistemática de literatura. Revista Produção Online, Florianópolis, SC, v.13, n. 1, p. 318-350, jan./mar. 2013.

URDAN, Flávio Torres; URDAN, André Torres. Gestão do composto de marketing. Editora Atlas. São Paulo - 2013.

WADA, Haruo. Gestão do trabalho: nova mentalidade. Folha de Londrina, Londrina, 28 jan 2002.

WAGNER III, John A. Comportamento organizacional. São Paulo: Saraiva 2002. 